\title{
RANCANGAN STRATEGI PENGEMBANGAN PRODUK TOKO HOTEI PUSAT GROSIR METRO TANAH ABANG
}

\author{
Carlos Francois Sopamena \\ Program Studi S2 Wijawiyata Manajemen \\ Sekolah Tinggi Manajemen PPM
}

\begin{abstract}
Hotei adalah toko busana yang didirikan pada Maret 2012. Kegiatan operasional yang dilakukan Toko Hotei adalah memproduksi busana jadi dengan brand sendiri serta menjual produk tersebut ke penjual eceran ataupun konsumen akhir langsung. Untuk dapat mempertahankan eksistensi di dalam persaingan bisnis diperlukan strategi bisnis jangka panjang agar dapat mengantisipasi segala macam kemungkinan yang ada di masa yang akan datang. Strategi bisnis jangka panjang ini mengarah kepada pengembangan produk (product development). Di dalam melakukan analisis strategi pengembangan bisnis Toko Hotei menggunkana beberapa analisis antara lain : analisis eksternal, analisis internal, matriks EFE, matriks IFE, matrik IE, Key Success Factors (KSF), QSPM. Hasil matriks EFE Tko Hotei adalah 2,925 dan hasil matriks IFE adalah 2.82, hal ini memposisikan matriks IE berada pada kuadran V. Pilihan strategi yang ada adalah pengembangan produk dan penetrasi pasar. Berdasarkan matriks QSPM pilihan strategi yang paling cocok dikembangkan Toko Hotei adalah strategi pengembangan prdouk dengan nama strategi "Woman On Top".
\end{abstract}

Keywords:

Strategi bisnis, pengembangan produk, wholesaling 


\section{PENDAHULUAN}

\subsection{Latar Belakang}

Hotei adalah toko busana yang didirikan pada Maret 2012. Kegiatan operasional yang dilakukan Toko Hotei adalah memproduksi busana jadi dengan brand sendiri serta menjual produk tersebut ke penjual eceran ataupun konsumen akhir langsung. Produk yang ditawarkan Toko Hotei adalah produk busana wanita dewasa dengan desain terkini, kualitas terjamin dan harga yang bersaing. Toko Hotei fokus pada kegiatan penjualan secara grosir (wholesaler) quantity produk yang ditawarkan di dalam jumlah yang cukup besar, Hal ini untuk memenuhi permintaan produk sampai ke daerah-daerah di luar JABODETABEK.

Produk yang ditawarkan Toko Hotei saat ini adalah fokus pada busana wanita dewasa, pengembangan produk yang akan dilakukan selanjutnya adalah Toko Hotei akan menambahkan lini produk yang baru dengan target pasar yang lebih spesifik yaitu Busana Ibu Hamil. Pemilihan lini produk yang baru ini didasari oleh hasil observasi pasar akan permintaan konsumen dari produk busana ibu hamil yang sangat besar di Pusat Grosir Metro Tanah Abang. Permintaan akan produk busana ibu hamil sangatlah besar dikarenakan jumlah pedagang yang menjual busana ibu hamil terutama dalam skala penjualan grosir di tanah abang masih relatif sedikit. Menurut data jumlah ibu hamil pada tahun 2010 adalah 4.809.860 jiwa dan diperkirakan terus meningkat sampai sebesar $\pm 15 \%$ pertahun sapai dengan tahun 2014 diperkirakan jumlah ibu hamil di Indonesia sebesar 5.290.235 jiwa.

Berdasarkan data tersebut, semakin banyaknya toko-toko retailer yang menjual busana ibu hamil modern yang sesuai dengan perkembangan fashion menjadi hal yang utama juga. Para ibu hamil membutuhkan busana yang dapat berfungsi sebagai busana dimasa kehamilan serta juga sekaligus tetap dapat kelihatan trendy dan stylish.

Untuk melakukan pengembangan bisnis melalui rencana pemilihan strategi product development ini diperlukan Business Plan agar pemilihan strategi tersebut memiliki kecocokan dengan kapabiltas Toko Hotei sendiri, kebutuhan dan tantangan industri yang dihadapi di masa yang akan datang. Dengan adanya Business Plan ini juga pengembangan usaha Toko Hotei semakin terarah dan jelas.

\subsection{Rumusan Masalah}

Setelah melihat kapabilatas Toko Hotei, serta melihat peluang pasar terhadap permintaan produk tertentu maka Toko Hotei perlu melakukan pengembangan strategi bisnis kedepannya yang fokus ke arah product development. Apakah strategi product development merupakan strategi yang cocok bagi Toko Hotei ? Bagaimana strategi product development tersebut dapat dijalankan dengan efektif dan efisien ?

\subsection{Tujuan Penulisan}

Tujuan pembuatan bisnis plan ini adalah untuk menetapkan strategi bisnis bagi Toko Hotei beberapa tahun yang akan datang yang dapat digunakan sebagai panduan dan arahan yang jelas di dalam menjalankan kegiatan bisnis dan juga diharapkan dengan adanya strategi bisnis dapat menciptakan competitive advantage bagi pengembangan bisnis Toko Hotei.

\section{TINJAUAN TEORI DAN PENGEMBANGAN HIPOTESIS}

\subsection{Manajemen Strategi}

Manajemen strategi menurut Fred.R.David (2011) didefinisikan sebagai ilmu tentang perumusan, pelaksanaan dan evaluasi keputusan-keputusan lintas fungsi 
yang memungkinkan organisasi mencapai tujuannya.

Tahapan-tahapan proses manajemen strategis yang dikemukakan oleh Fred. R. David (2011), :

a. Analisis lingkungan eksternal

Analsis lingkungan eksternal bertujuan untuk mengidentifikasi dan mengevaluasi kecendrungan kejadian - kejadian yang berada diluar kontrol perusahaan yang harus dihindari. Analisis eksternal yang dilakukan terdiri dari analisis Poter's 5 Forces (Kemenarikan Industri) dan analisis PESTEL (Analisis Makro). Analisis Makro terkait dengan faktorfaktor umum yang terkait dengan faktor politik,ekonomi, sosial Beberapa faktor yang terkait dengan analisis Poter's 5 Forces adalah Rivaly Among Existing Competitors, Threat of New Entrants, Threat of Subsitute Product or Service, Bargaining Power of Suppliers, Bargaining Powers of Buyers. Output dari kedua analisis tersebut adalah peluang dan ancaman dalam lingkungan eksternal. Hasil faktor peluang dan ancaman ini digunakan untuk merumuskan matriks EFE yang menggambarkan kemampuan responsif perusahaan di dalam memanfaatkan peluang serta menghindar dari ancaman yang mungkin muncul.. Analisis industri yang ada juga dapat digunakan sebagai alat untuk memperoleh KSF (Key Success Factor) kunci faktor keberhasilan di dalam menghadapi persaingan di dalam suatu industri.

b. Analisis lingkungan internal

Analisis lingkungan internal berguna untuk merumuskan kekuatan serta kelemahan yang dimilki perusahaan tersebut. Kekuatan adalah suatu kondisi perusahaan yang mampu melaksanakan operasional usaha dengan baik karena memiliki sumber daya, keterampilan, serta keunggulan lain yang berhubungan dengan pesaing. Sedangkan kelemahan adalah suatu kondisi dimana perusahaan kurang mampu menjalankan operasional perusahaan dengan baik karena adanya kendala sumber daya, kinerja efektif perusahaan. Di dalam memperoleh faktor kekuatan dan kelemahan dari perusahaan dapat dilakukan dengan Analisis Fungsional yang fokus menjabarkan kekuatan-kelemahan perusahaan berdasarkan masing-masing fungsi manajemen yang terkait.. Dari pengolahan terhadap metode tersebut didapatkan beberapa faktor kekuatan dan kelemahan yang dimilki perusahaan. Melalui beberapa faktor internal yang sudah dikumpulkan dirumuskanlah Matriks IFE. Matriks IFE menggambarkan kapabilatas perusahaan terutama di dalam kekuatan dan kelemahan yang dimiliki perusahaan.

c. Analisis TOWS

Analisis TOWS bertujuan untuk melihat hubungan yang saling dikaitkan dengan strategi di dalam menghadapi peluang,ancaman, kekuatan dan kelenahan yang dimiliki perusahaan untuk dapat menciptakan beberapa alternatif strategi. Berikut kombinasi yang diperoleh dari pemilihan strategi yang ada : (1) SO (Kekuatan -Peluang) Strategi yang memanfaatkan kekuatan perusahaan (internal) untuk menghadapi peluang (eksternal) yang ada, (2) ST (Kekuatan Ancaman) Strategi yang memanfaatkan kekuatan perusahaan (internal) untuk menghindari ancaman (eksternal)yang akan terjadi. (3)WO (Kelemahan Peluang) Strategi untuk memperbaiki kelemahan perusahaan (internal) untuk menangkap peluang (eksternal) yang ada. (4)WT (Kelemahan - Ancaman) Strategi untuk memperbaiki kelemahan 
perusahaan (internal) untuk menghindari ancaman (eksternal) yang ada.

d. Matriks internal-eksternal

Matriks yang membandingkan antara Matriks EFE dan Matriks IFE yang menggambarkan faktor peluang,ancaman serta kekuatan, kelemahan. Matriks ini terdiri dari 9 kuadran yang dibagi kedalam 3 divisi strategi yang berbeda sesuai dengan kapabilitas perusahaan didalam menghadapi peluang serta ancaman melalui kekuatan dan kelemahan yang dimiliki perusahaan. Ketiga divisi strategi tersebut antara lain : Grow \& Build (kuadran I,II,IV) dalam posisi ini pilihan strategi yang tersedia adalah market penetration, market development, product development, backward, forward integration. Hold \& Maintain (kuadran III,V,VII) strategi piliha yang tersedia adalah market penetration dan product development. dan Harvest \& Divest (kuadran VI,VIII,IX).

e. Matriks QSPM (Quantitative Strategic Planning Matrix)

QSPM menurut Fred.R.David (2011) adalah alat yang memungkinkan penyusunan strategi untuk mengevaluasi alternatif strategi secara objektif, berdasarkan faktor keberhasilan kunci internal dan eksternal yang telah diidentifikasi sebelumnya.Teknik ini secara objektif mengindikasikan alternatif strategi mana yang terbaik. QSPM menggunakan input dari analisis Matriks EFE SWOT, Matriks IFE, Matriks Profil Kompetitif (CPM), Matriks IE yang dibutuhkan untuk membuat QSPM.

Secara konsep, QSPM menentukan daya tarik relatif dari berbagai strategi berdasarkan seberapa jauh faktor keberhasilan kunci internal dan eksternal dimanfaatkan atau diperbaiki. Daya tarik relatif dari masing-masing strategi dalam satu set alternatif dihitung dengan menentukan pengaruh kumulatif dari masing-masing faktor keberhasilan kunci eksternal dan internal.

Dari teori tersebut maka dibuatlah kerangka berpikir seperti pada Gambar 1. Di bawah ini untuk melakukan analisa dan membuat strategi bisnis Toko Hotei : 


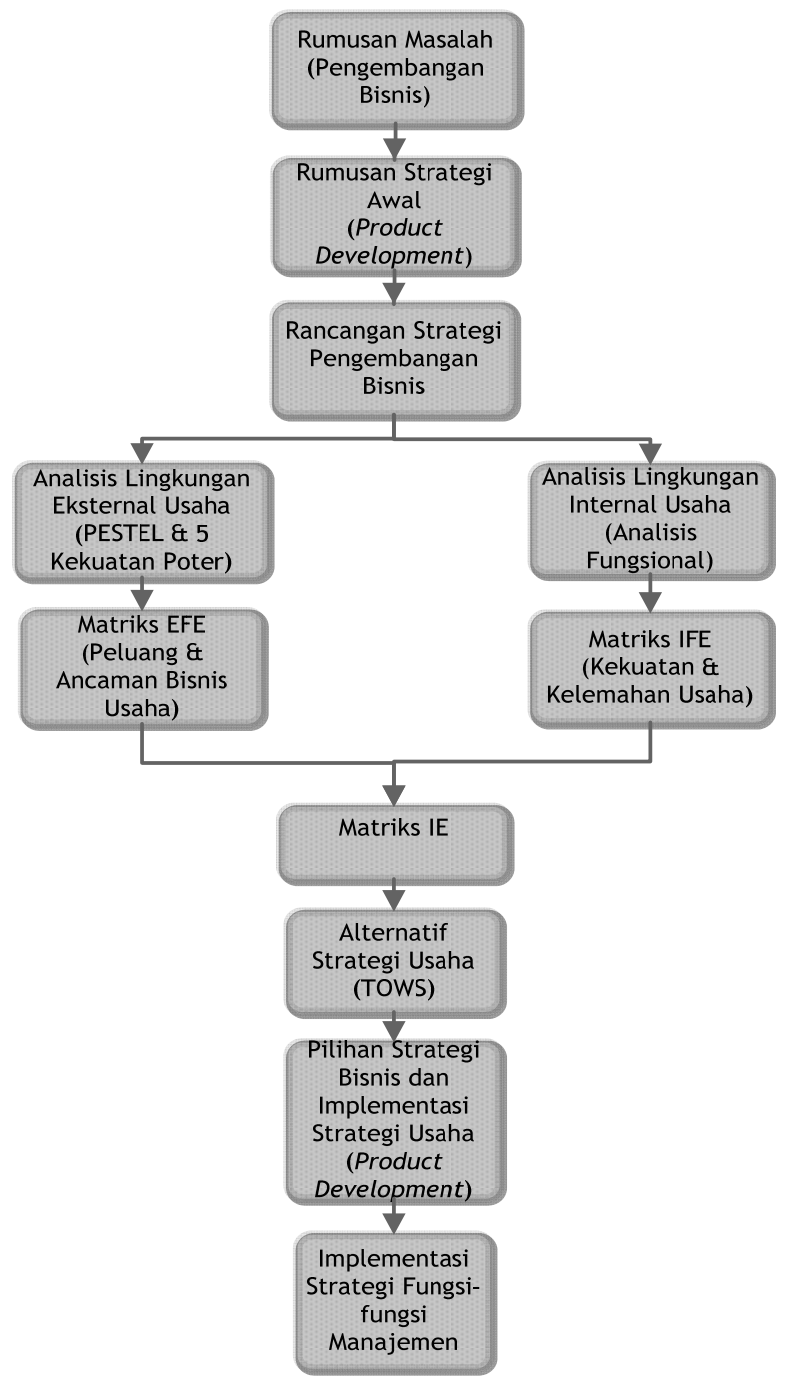

Gambar 1.

Kerangka Berpikir Penelitian

\section{METODE PENGUMPULAN DATA}

Metode yang digunakan untuk mendapatkan data primer dalam proses penyusunan rancangan strategi usaha adalah sebagai berikut :

a. Observasi kegiatan bisnis operasional Toko Hotei, obesrvasi kegiatan operasional toko relasi-relasi maupun pesaing-pesaing Toko Hotei.

b. Wawancara dengan pelaku bisnis yang sudah berpengalaman di dalam bisnis perdagangan pakaian grosir untuk mendapatkan data-data yang relevan.

c. Observasi dan wawancara dengan beberapa customer untuk memperoleh 
data-data yang konkrit tentang perkembangan bisnis.

Data sekunder, diperoleh dari bukubuku, internet dan data internal objek penelitian. Data sekunder mendukung data primer di dalam melakukan analisa internal maupun eksternal kegiatan bisnis. Jenis analisa yang digunakan adalah analisa kualitatif yaitu analisa internal (analisis fungsional) dan analisis eksternal (analisis industri dan analisis makro).

\section{PEMBAHASAN}

\subsection{Matriks EFE}

Berdasarkan hasil perhitungan EFE Matrix dan IFE Matriks, diketahui bahwa total point yang didapat adalah 2,925 untuk EFE hal ini menunujukakan kemampuan responsif perusahaan di dalam memanfaatkan peluang serta menghindari ancaman yang muncul sangat baik. Sedangkan untuk matriks IFE hasil yang di dapat adalah 2,82, hal ini mengindikasikan bahwa posisi internal usaha memiliki kapabilatas yang cukup baik.

Analisis internal (fungsional) dan analisis eksternal (analisis industri dan analisis makro) berguna untuk memperoleh data-data kekuatan, kelemahan, peluang dan ancaman yang berguna untuk menyusun rancangan strategi bisnis. Dari analisis internal dan eksternal tersebut diperoleh susunan daftar kekuatan, kelemahan, peluang dan ancaman sebagai berikut :

- Kekuatan

- Toko Hotei didukung Sumber Daya Manusia yang berpengalaman di dalam perdagangan pakaian grosir.

- Distribusi barang yang baik dari supplier ke gudang tempat penyimpanan maupun toko.
- Networking supplier yang luas yang menyediakan bahan baku yang berkualitas dengan harga yang bersaing.

- Konveksi yang berpengalaman.

- Sumber pendanaan investasi yang baik.

- Promosi yang efektif menggunakan beberapa media online seperti $B B M$ Group Messanger dan Facebook dengan biaya promosi yang murah.

- Harga relatif terjangkau.

- Kelemahan

- Quality Control yang kurang menyebabkan banyak cacat produksi.

- Jumlah konveksi mengurangi kapasitas produksi.

- Brand Awareness yang lemah.

- Lokasi toko kurang strategis.

- Produk yang ditawarkan masih sedikit terutama di dalam jumlah variasi produk dan juga kuantitas yang ditawarkan.

- Peluang

- Pelaksanaan otonomi daerah berdampak pada peningkatan taraf hidup masyarakat di daerah yang merupakan target pasar utama.

- Pertumbuhan kaum middle-class di Indonesia yang semakin meningkat.

- Perkembangan teknologi dan komunikasi internet mendorong inovasi penjualan online.

- Pemberlakuan China-AFTA.

- Ancaman

- Kenaikan biaya produksi akibat kenaikan tarif dasar listrik.

- Persaingan antara produk lokal dan produk import.

- Pembangunan pusat-pusat perbelanjaan grosir yang baru menambah peta persaingan bisnis. 


\section{2}

Matriks IE

Berdasarkan hasil perhitungan EFE Matrix dan IFE Matriks, diketahui bahwa total point yang didapat adalah 2,925 untuk EFE dan 2,82 untuk IFE. Sehingga dalam IE matriks posisi Toko Hotei berada pada kuadran ke $\mathrm{V}$, bisnis usaha yang berada pada kuadran ke $\mathrm{V}$ merupakan bisnis usaha yang berada pada tahap hold and maintain, sehingga strategi bisnis pilihan yang cocok bagi Toko Hotei adalah strategi market penetration dan product development.

\subsection{Matriks TOWS}

Berdasarkan hasil alternatifalternatatif strategi yang ada. Toko Hotei melakukan pengelompokan terhadap strategi-strategi yang selaras dua strategi besar yaitu, pertama "Woman On Top", strategi ini fokus kepada pengembangan lini produk yang lebih spesifik melayani target konsumen yang ada, tetapi fokus pada pasar wanita dewasa. Hal-hal yang dilakukan adalah : menambah produk import, membuat unit bisnis baru (konveksi) dengan memproduksi barang sendiri. Strategi yang kedua adalah "Up In The Sky” strategi ini fokus pada promosi produk untuk menciptakan brand awareness melalui media internet untuk merangsang konsumen untuk membeli produk yang ditawarkan Toko Hotei, hal-hal yang dilakukan antara lain : masuk ke pasar retail lewat media online, penjualan online secara grosir.

\subsection{Matriks QSPM}

Langkah selanjutnya adalah menentukan strategi yang cocok digunakan. Hasil matriks QSPM menunjukan bahwa strategi "Women On Top" memiliki nilai yang lebih tinggi yaitu 3,105. Hal in berarti pilihan strategi usaha yang paling cocok diimplementasikan oleh Toko Hotei beberapa tahun mendatang adalah strategi “Woman On Top”.
Strategi ini mempunyai makna pengembangan produk yang dilakukan Toko Hotei akan fokus ke target pasar yang dimiliki yaitu wanita dewasa dengan cara memberikan produk terbaik yang fokus terhadap wanita dewasa dengan menawarkan beberap lini produk yang berbeda. Pengembangan produk yang dilakukan Toko hotei adalah menambahkan inovasi produk yaitu busana wanita hamil grosir. Diharapkan dengan penambahan lini produk akan meningkatkan penjualan di masa yang akan datang. Pengembangan produk ini juga di dorong oleh kemampuan Toko Hotei sendiri yaitu memiliki supplier (konveksi) yang memiliki kapabilitas yang sangat baik di dalam melakukan produksi barang yang berkualitas. Langkah selanjutnya adalah mengimplementasikan strategi "Woman On Top” ke dalam aspek-aspek manajemen yang terkait.

\section{IMPLEMENTASI STRATEGI}

Metode perumusan rancangan strategi bisnis menggunakan matrik QSPM memilih strategi "Women On Top" sebagai strategi pilihan yang mengarah pada strategi pengembangan produk yang sesuai dengan rumusan strategi awal Toko Hotei. Melalui strategi pengembangan produk itulah dibuat implementasi strategi berdasarkan masingmasing aspek manajemen. Berikut implementasi strategi masing-masing aspek :

\subsection{Strategi Operasional}

Implementasi strategi “Woman On Top" pada aspek operasional terkait dengan proses bisnis yang dimiliki Toko Hotei. Setiap tahapan proses bisnis memiliki strategi masing-masing. Beberapa strategi tersebut antara lain :

- Penambahan Lini Produk Baru : fokus pada penambahan produk busana hamil. 
Program aktivitas : menggunakan jasa designer outsource di dalam mendesign baju hamil, mengikuti trend perkembangan busana hamil di pasar retail.

- Peningkatan Qualitas : fokus pada pemilihan bahan.

Program aktivitas : Pemilihan bahan katun tipis untuk menjaga kualitas serta kenyamanan konsumen.

- Perencanaan produksi : fokus pada penjadwalan produksi.

Program aktivitas : pembagian jadwal kerja konveksi, memberikan daftar prioritas barang produksi.

- Sistem diversivikasi penjualan : fokus pada pembagian penjualan produk.

Program aktivitas : perbedaan peluncuran hari produk baru antara busana hamil dan busana wanita dewasa.

- Sistem inventory baru : fokus pada pengendalian inventory dan penyimpanan. Program aktivitas : pembagian gudang penyimpanan, membedakan sistem pencatatan inventory, perbedaan pencatatan nota.

\subsection{Strategi Pemasaran}

Implemetasi strategi pemasaran

Toko Hotei di dalam sinerginya dengan strategi "Woman On Top" terkait dengan aspek bauran pemasaran yang dimiliki Toko Hotei yaitu : product, price, place dan promotion. Elemen-elemen tesebut menjadi tolak ukur di dalam peningkatan aspek manajemen pemasaran yang mendukung strategi bisnis "Woman On Top" yang dirumuskan. Berikut implementasi strategi pemasaran :

- Produk diferensiasi : fokus pada pembagian lini produk dan pengembangan produk baru.

Program aktivitas : penjualan produk busana hamil ke konsumen akhir, toko busana hamil.
- Penetapan harga yang kompetitif : fokus pada penentuan harga yang sesuai dengan kualitas yang ditawarkan.

Program aktivitas : penentuan harga yang kompetitif sesuai fungsi dan manfaat busana hamil.

- Distribusi terfokus : distribusi langsung ke toko-toko reseller.

Program aktivitas : Distribusi produk langsung ke toko-toko ibu hamil maupun toko peralatan bayi.

- Media Online : fokus pada pengembangan websites.

Program aktivitas : pembuatan websites, melakukan penawaran produk di websites tersebut dan juga pemberian informasi dimasa kehamilan, meningkatkan brand awareness.

\subsection{Strategi Sumber Daya Manusia}

Implementasi strategi "Woman On

Top” pada aspek daya sumber daya manusia adalah pada elemen pelatihan dan pengembangan serta penilaian kinerja karyawan, pemiliha elemen tersebut karena inisiatif strategi di dalam kedua elemen tersebut mendukung strategi bisnis yang dirumuskan Toko Hotei. Berikut implementasi strategi sumber daya manusia tersebut :

- Pembuatan sistem Training \& Development sederhana : fokus pada transfer knowledge dan product knowledge.

Program aktivitas : melakukan transfer knowledge langsung ke karyawan di dalam penjualan, memberikan pengetahuan terhadap produk kepada karyawan terutama produk baru.

- Pembuatan sistem penilaian kinerja : fokus pada reward \& punishment dan performance appraisal.

Program aktivitas : memberikan reward kepada karyawan yang memiliki kinerja yang baik, membuat sistem penilaian 
karyawan yang berisi : absensi, kecepatan menyelesaikan pesanan, pelayanan terhadap pelanggan.

\subsection{Strategi Keuangan}

Implementasi pilihan strategi usaha Toko Hotei “Woman On Top” sangat erat kaitannya dengan aspek keuangan. Karena di dalam melakukan strategi pengembangan usaha diperlukanlah strategi keuangan yang baik terutama dalam hal investasi pendanaan serta efek strategi bisnis pilihan tersebut terhadap peningkatan penjualan. Oleh karena itu penetapan strategi beradarkan elemen investasi dan proyeksi penjualan. Berikut inisiatif strategi dari masing-masing elemen terkait :

- Diversifikasi Investasi : fokus pada pembagian investasi antara produk wanita dewasa dan produk busana hamil.

Program aktivitas : investasi dana terhadap dua produk yang berbeda, investasi pada pengembangan unit bisnis yang baru.

- Penetapan Target Penjualan ; fokus pada rencana proyeksi penjualan setiap bulan dan proyeksi permintaan.

Program aktivitas : proyeksi rencana penjualan setiap bulannya, proyeksi total penjualan tahunan, proyeksi terhadap pernintaan.

\section{KESIMPULAN}

Menurut proses manajemen strategi, rancangan strategi bisnis yang cocok dan sesuai dengan kapabilitas Toko Hotei sesuai dengan kekuatan, kelemahan, peluang dan ancaman yang dihadapi. Diharapkan juga rancangan strategi ini dapat menjadi suatu arahan dan panduan di dalam menjalankan kegiatan bisnis usaha Toko Hotei, karena di dalam rumusan strategi ini sudah dirumuskan juga tindakan implementasi terhadap masing-masing aspek manajemen yang ada di Toko Hotei dan juga aktivitas operasional sehari-hari yang dilakukan di dalam menjalankan strategi bisnis tersebut. Diharapkan juga di dalam menjalankan strategi pilihan tersebut Toko Hotei dapat menciptakan suatu keunggulan kompetitif yang dapat dijadikan sebagai alat untuk menghadapi persaingan di dunia penjualan pakain grosir yang sangat ketat. Tentunya juga rumusan strategi tersebut dapat diimplementasikan di dalam dunia bisnis yang nyata sebagai suatu pedoman di dalam menjalankan kegiatan bisnis jangka panjang maupun kegiatan jangka pendek, serta dapat meningkatkan profit Toko hotei menjadi bisnis toko yang dapat selau berkembang menghadapi persaingan dalam usaha bisnis penjualan pakaian grosir. 


\section{DAFTAR PUSTAKA}

Berman, Barry.,Joel R.Evans (2010). Retail Management (11 ${ }^{\text {th }}$ ed). Pearson : Prentice Hall David, Fred R (2011). Strategic Management (13 ${ }^{\text {th }}$ ed), Pearson : Prentice Hall

http://www.infodokterku.com (diunduh 5 Agustus 2012)

Kotler, Philip.,Keller, Kevin Lane (2011). Marketing Management $\left(13^{\text {th }}\right.$ ed),Pearson : Prentice Hall 